\title{
Effect of grain size on belt finishing process of hardened steel parts
}

\author{
[Abdeljabar Khellouki]
}

\begin{abstract}
Belt finishing of hardened steel parts begins to integrate the automotive and the aeronautic industry as an alternative to classical superfinishing process. However his practice in industry is always uncertain because research in this topic is at the beginning. This paper is a contribution to the understanding of belt finishing mechanisms by using an experimental approach to study especially the effect of grain size on roughness and on specific energy. It was demonstrated that with the increase of grain size the roughness increases while the specific energy decreases. However the grain size must be chosen strictly to have a good surface topography. Moreover with small grains, friction and ploughing is larger than cutting and specific energy is very important. With large grains specific energy is small and spent essentially in cutting.
\end{abstract}

Keywords - belt finishing, grain size, specific energy, abrasive belt, hardened steel.

\section{Introduction}

Belt finishing is a new superfinishing process in mechanical industry. This operation consists in pressing a thin abrasive belt against a rotating workpiece surface by means of an elastic polymer roller. At the same time, the abrasive belt oscillates in the axial direction and moves slowly in the tangential direction as shown in Fig. 1.

Researches on belt finishing are limited. The effects of the structural characteristics of the abrasive belt on finishing performances have not yet been fully explained. Thus, practice of belt finishing in industry is always uncertain.

However, it was already shown that belt finishing process is complementary to hard turning. Belt finishing could correct the defects induced by hard turning as tensile residual stress, metallurgical modifications and roughness defects [1-5].

A study about the interaction between lubrication mode and film feed rate has demonstrated that with Minimum Quantity Lubrication (MQL) at low belt feed rate the grains are cut off from the backing and a slurry is formed. The belt finishing in these conditions is similar to lapping [6].

This paper is a contribution to understanding the belt finishing mechanisms by studying the grain size effect at normal conditions. Experimentations were made on hardened steel alloy AISI 52100 (100Cr6) used in automotive and aeronautic manufacturing (crankshaft, camshaft, valves...etc).

Abdeljabar Khellouki.

Ecole Nationale Supérieure d'Arts et Métiers / University Moulay Ismail. Meknès, Morocco.

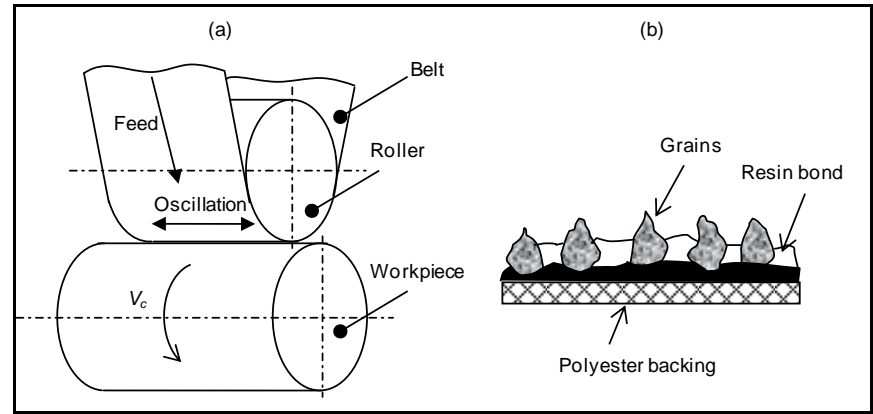

Figure 1. Belt finishing principle: (a) belt finishing movements and (b) abrasive belt structure.

\section{Experimental procedure}

The samples used in this series of experiments are made of hard steel alloy AISI 52100 hardened and tempered to 62 HRC. The cylindrical samples are prepared by hard turning with triangular Cubic Boron Nitride inserts (C-BN, nuance: TNGA 160408 S 01020). Fig. 2 (a) shows the experimental setup for hard turning.

The cutting conditions of hard turning are:

- Cutting speed, $\mathrm{V}_{\mathrm{C}}=120 \mathrm{~m} / \mathrm{min}$.

- $\quad$ Feed rate, $\mathrm{f}=0.1 \mathrm{~mm} / \mathrm{rev}$.

- $\quad$ Depth of cut, $\mathrm{a}_{\mathrm{p}}=0.3 \mathrm{~mm}$.

- Without lubrication.

The arithmetic average roughness after hard turning is about: $\mathrm{Ra}_{\text {moy }}=0.27 \mu \mathrm{m}$.

To estimate the effect of grain size on the surface roughness, tests were conducted on samples obtained by hard turning by varying the grain size from $9 \mu \mathrm{m}$ to $80 \mu \mathrm{m}$. Fig. 2 (b) shows the experimental setup.

Belt finishing conditions are as follows:

- Cutting speed, $\mathrm{V}_{\mathrm{C}}=160 \mathrm{~m} / \mathrm{min}$.

- $\quad$ Normal applied force, $\mathrm{F}_{\mathrm{N}}=310 \mathrm{~N}$ (Pressure $=2$ bar)

- Belt feed rate, $\mathrm{f}=32 \mathrm{~mm} / \mathrm{min}$.

- $\quad$ Roller oscillation frequency, $\mathrm{n}_{\mathrm{osc}}=12 \mathrm{~Hz}$.

- Oscillation amplitude, $\mathrm{a}_{\mathrm{osc}}=3 \mathrm{~mm}$.

- $\quad$ Roller hardness, $\mathrm{H}_{\mathrm{S}}=90$ Shore A.

- Minimum Quantity lubrication by "Dialub R5” oil. 
Proc. of the Third Intl. Conf. on Advances in Mechanical, Aeronautical and Production Techniques - MAPT 2015

Copyright (C) Institute of Research Engineers and Doctors, USA .All rights reserved.

ISBN: 978-1-63248-059-0 doi: 10.15224/ 978-1-63248-059-0-71

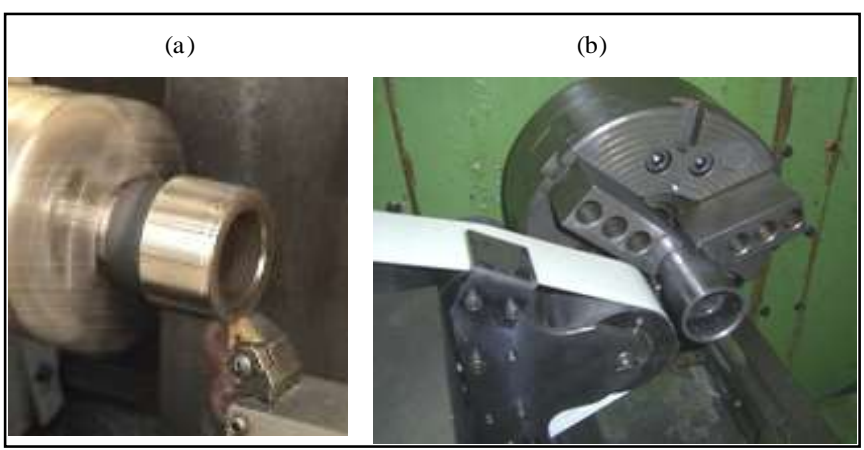

Figure 2. Experimental setup: (a) hard turning and (b) belt finishing.

\section{Results and discussion}

\section{A. Effect on roughness}

In Fig. 3, one can see that the evolution of arithmetic average roughness parameter $\mathrm{Ra}$ versus grain size follows two steps: a first very brief period when the roughness decreases to a minimum at $15 \mu \mathrm{m}$ and a second period when the roughness increases continuously. Thus, an abrasive belt of $15 \mu \mathrm{m}$ gives best results than an abrasive belt of $9 \mu \mathrm{m}(\mathrm{Ra}=0.04 \mu \mathrm{m})$ which seems to be contradictory. The explication of this phenomenon is that with abrasive belt of $9 \mu \mathrm{m}$, the so fine grains can't penetrate deeply on the matter and can't consequently plow entirely the rough profile from hard turning. Thus, the profile corresponding to belt finishing with $9 \mu \mathrm{m}$ shown in Fig. 4 has a coarser shape than profile corresponding to belt finishing with $15 \mu \mathrm{m}$. Fig. 5 shows Bearing Area Curves, called also Abbott-Firestone curves [7], that could be built by computing the cumulative probability density function of the surface profile's height by integrating the profile trace [8]. Abbott-Firestone curve is usually used to evaluate surfaces topography by comparing their smoothness and their bearing characteristics. From Fig. 5, one can see that the curve of $15 \mu \mathrm{m}$ is below the curve of $9 \mu \mathrm{m}$ with a flatter slope which means that belt finishing with $15 \mu \mathrm{m}$ gives better bearing characteristics (smoother plateau, relatively deep scratches to hold and distribute lubricant...etc) than belt finishing with $9 \mu \mathrm{m}$. As a first conclusion one can say that it is not always recommended to make belt finishing directly with very fine grains on surface from machining.

From $15 \mu \mathrm{m}$ belt finishing roughness increases and from $60 \mu \mathrm{m}$ belt finishing roughness becomes even larger than original hard turning roughness (Fig. 3). The Abbot-Firestone curve of Fig. 5 shows that the curve of $80 \mu \mathrm{m}$ is above the curve corresponding to hard turning which means that the bearing parameters of belt finishing are worse than the bearing parameters of the original machining operation.

One can say that to make a good belt finishing the belt grain size must be chosen according to the initial surface roughness. Grains finer than required do not necessarily improve the original roughness and grains larger than required can damage the surface resulting in a roughness worse than the original roughness. A process that includes a rough belt finishing followed by a finish belt finishing can be also envisaged.

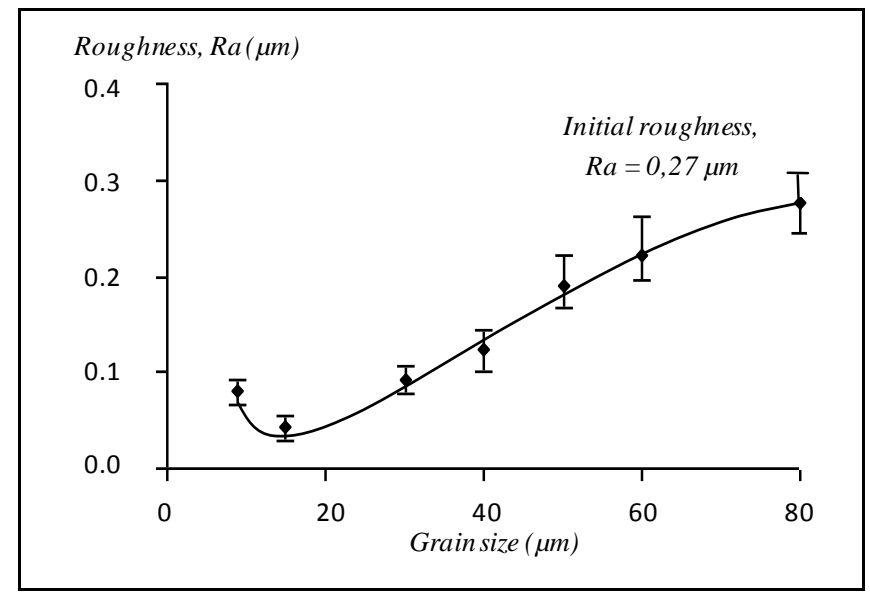

Figure 3. Belt finishing roughness versus grain size (belt finishing conditions : cutting speed $V_{C}=160 \mathrm{~m} / \mathrm{min}$, applied force $F_{N}=310 \mathrm{~N}$, belt feed $\mathrm{f}=32 \mathrm{~mm} / \mathrm{min}$, oscillation $\mathrm{n}_{\mathrm{osc}}=12 \mathrm{~Hz}$, roller hardness $\mathrm{H}_{\mathrm{S}}=90$ shore $\mathrm{A}$, lubrication : MQL).

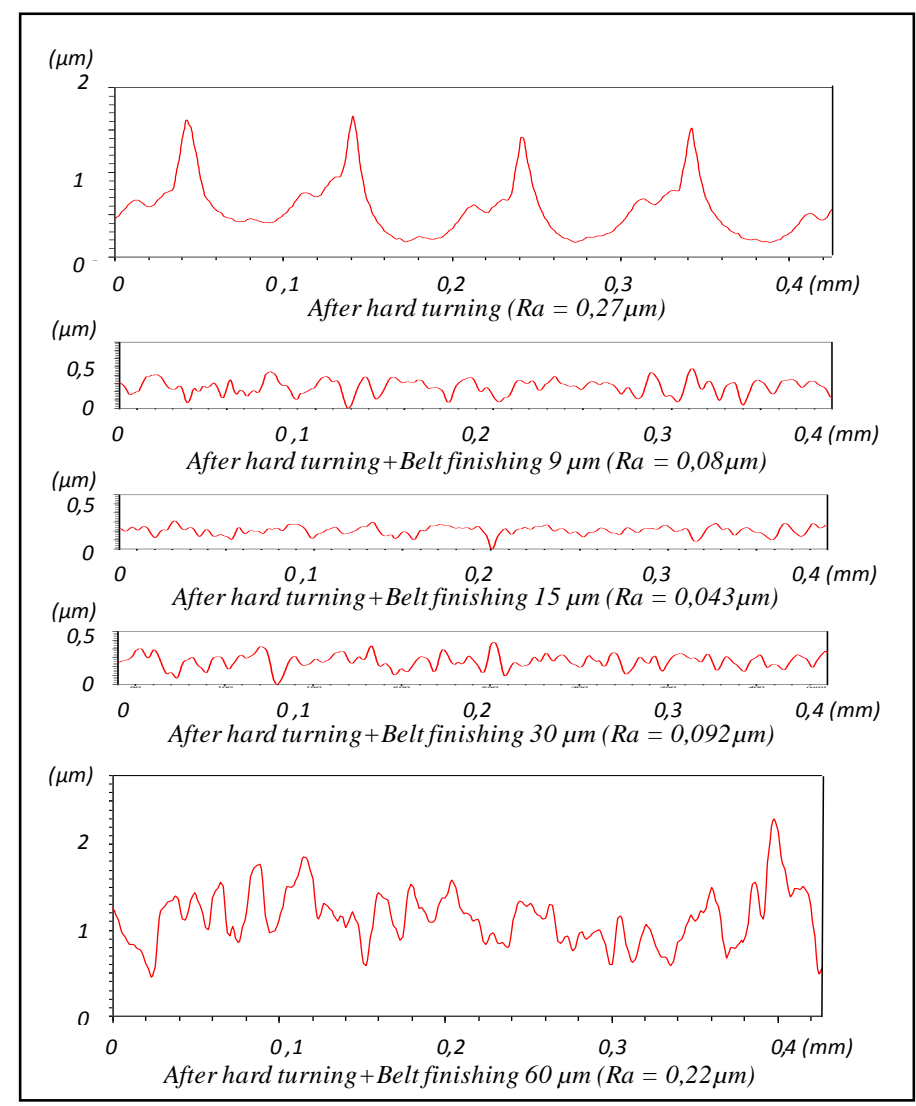

Figure 4. Roughness profile of hard turning and roughness profiles of belt finishing for different grain size (belt finishing conditions: see Fig. 3).

\section{B. Effect on specific energy}

Fig. 6 shows that as the grain size of the abrasive belt increases the material removal in belt finishing (represented by the diametral reduction of the workpiece) increases. At $9 \mu \mathrm{m}$ the material removal is less than $0.5 \mu \mathrm{m}$ which is extremely low. At $100 \mu \mathrm{m}$ the material removal reaches $14 \mu \mathrm{m}$ which is very important. Indeed, with the increase of grain size the 
depth of cut increases, thus the cutting mechanisms become very important with large grain size.

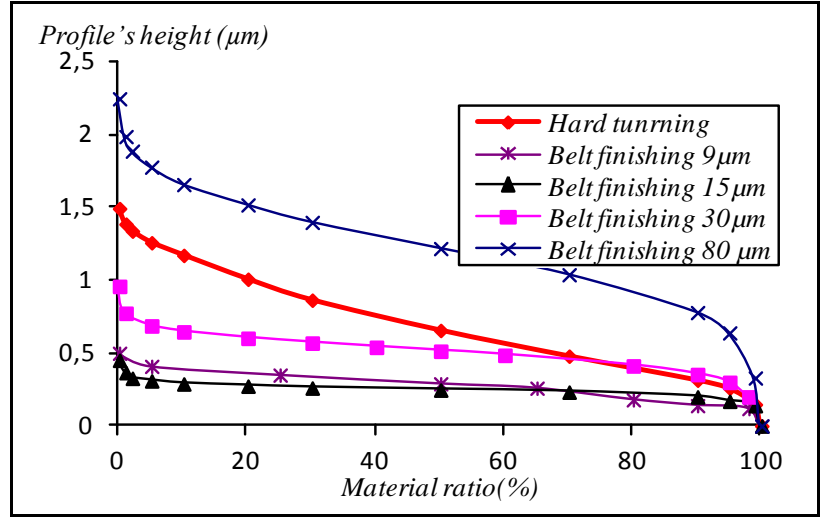

Figure 5. Abbott-Firestone curve after hard turning and after belt finishing with different grain size (belt finishing conditions: see Fig. 3).

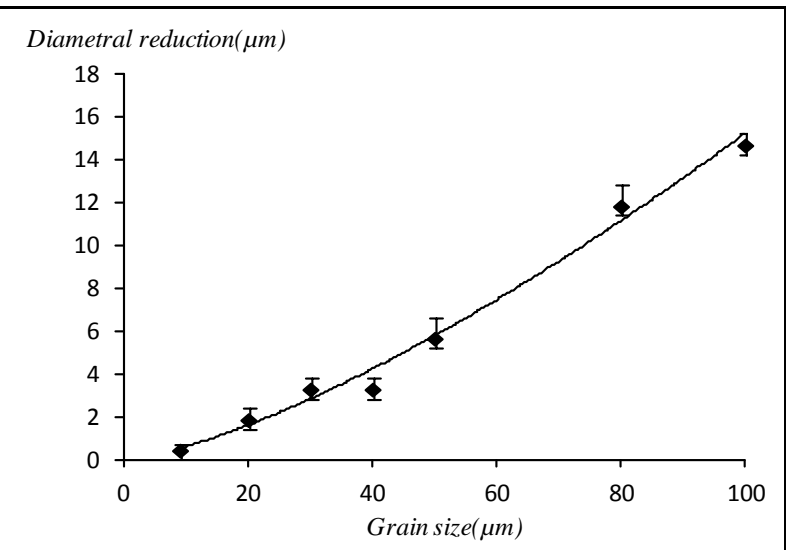

Figure 6. Diametral reduction in belt finishing versus grain size (belt finishing conditions: workpiece dimensions: $\varnothing=45 \mathrm{~mm}, \mathrm{~L}=35 \mathrm{~mm}$, cutting speed $\mathrm{V}_{\mathrm{C}}=160 \mathrm{~m} / \mathrm{min}$, applied force $\mathrm{F}_{\mathrm{N}}=310 \mathrm{~N}$, belt feed $\mathrm{f}=32 \mathrm{~mm} / \mathrm{min}$, oscillation $\mathrm{n}_{\mathrm{osc}}=12 \mathrm{~Hz}$, roller hardness $\mathrm{H}_{\mathrm{S}}=90$ shore A, lubrication: Minimum Quantity Lubrication).

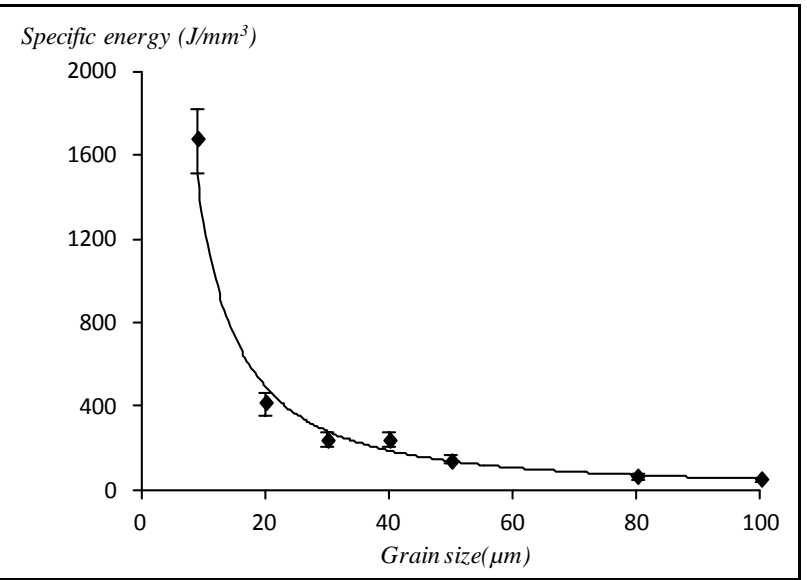

Figure 7. Specific energy in belt finishing versus grain size (belt finishing conditions: see Fig. 6).

To quantify the energy dissipated per unit of material removed the specific energy is used. This parameter is defined as follows:

$$
\mathrm{E}_{\mathrm{S}}=\mathrm{F}_{\mathrm{T}} \cdot \mathrm{V}_{\mathrm{T}} / \mathrm{Q}_{\mathrm{W}}
$$

With:

- $\quad \mathrm{F}_{\mathrm{T}}$ : Tangential force $[\mathrm{N}]$.

- $\quad \mathrm{V}_{\mathrm{T}}$ : Tangential speed $[\mathrm{m} / \mathrm{s}]$.

- $\mathrm{Q}_{\mathrm{W}}$ : Material removal rate $\left[\mathrm{mm}^{3} / \mathrm{s}\right]$.

This overall specific energy can be divided into three components namely: friction specific energy $\mathrm{E}_{\mathrm{S}, \mathrm{F}}$, ploughing specific energy $E_{S, P}$ and cutting specific energy $E_{S, C}$ :

$$
\mathrm{E}_{\mathrm{S}}=\mathrm{E}_{\mathrm{S}, \mathrm{F}}+\mathrm{E}_{\mathrm{S}, \mathrm{P}}+\mathrm{E}_{\mathrm{S}, \mathrm{C}}
$$

Friction process is occurred when grains rub on the workpiece surface rather than cutting due to the elastic deformation of the system. As the elastic limit between the abrasive grain and workpiece is exceeded, plastic deformation takes place and ploughing stage is reached. Therefore workpiece material flows plastically through forward and sideward ahead of the abrasive grain and forms a groove. When the workpiece material cannot resist the flow stress, chip is formed. The chip formation is called cutting. In this chip formation stage, energy is used most efficiently [9-11].

Fig. 7 shows that the overall specific energy decreases with the grain size. For small grains the specific energy is very important despite the low cutting capacity while for larger grains the specific energy is very low despite the large cutting capacity. One can say that friction and ploughing specific energy in belt finishing is very high in comparison to cutting specific energy. Thus, for small grain size friction and ploughing are very important comparing to cutting, which explains the importance of overall specific energy. On the other hand, for large grain size friction and ploughing specific energy are negligible which explain the low overall specific energy level.

Furthermore, it was found that small grains always give better surface roughness than larger grains. It is likely that during belt finishing process roughness becomes better when friction and ploughing are predominant than cutting. The affirmation of this observation could be done through further investigations into the cutting mechanisms of belt finishing.

\section{Conclusion}

The grain size is a critical parameter in belt finishing process. The grain size must be chosen carefully to ensure good surface roughness and good bearing parameters. Extremely fine grains do not necessarily make a good belt finishing on a rough surface because they cannot remove the entire profile from the previous machining. Moreover, with very large grain size belt finishing gives a roughness worse than the original one. Furthermore, it was found that for small particle size the specific energy is very important and essentially spent in ploughing and friction. On the other hand, for large grain size the specific energy is low and essentially spent in cutting.

\section{References}

[1] J. Rech and A. Moisan, "Surface integrity in finish hard turning of casehardned steels," Int. J. Mach. Tools Manuf, 2003, vol. 43, pp. 543-550. 
[2] A. Khellouki, J. Rech and H. Zhouani, "Influence of the belt finishing process on the surface texture obtained by hard turning," Proc. Inst. Mech. Eng, Part B: J. Eng. Manuf, vol. 221, № 7/2007, pp.1129-1137, 2007.

[3] J. Rech and A. Moisan, "Belt grinding, a way to optimise the surface integrity of cut surfaces," Conference Internationale MMSS, pp. 23-26 Krakow (Poland), ISBN 83-912887-5-7, nov 2003.

[4] J. Rech, G. Kermouche, C. Claudin, A. Khellouki and W. Grzesik, "Characterization and modelling of the residual stresses induced by belt finishing on a AISI52100 hardned steel," J. Mater. Proces. Tech, vol. 208, N ${ }^{\circ} 1-3$, pp. 187-195, 2008.

[5] W. Grzesik and T. Wanat, "Surface finish generated in hard turning of quenched alloy steel parts using conventional and wiper ceramic inserts," Int. J. Mach. Tools Manuf, vol. 47, pp. 255-262.

[6] A. Khellouki, J. Rech and H. Zhouani, "The effect of lubrication conditions on belt finishing," Int. J. Mach. Tools Manuf, vol. 50, Issue 10, pp. 917-921, 2010

[7] E.J. Abbott, F.A. Firestone, "Specifying surface quality," Mech. Eng, vol. 59, pp. 569-572, 1993.

[8] G. W. Stachowiak and A.W. Batchelor, "Engineering tribology," Boston :Butterworth-Heinmann, ISBN 0-7506-7304-4.

[9] H. Demir, A. Gullu, I. Ciftci and U. Seker, "An Investigation into the influences of grain size and grinding parameters on surface roughness and grinding forces when grinding," J. Mech. Eng., vol. 56, $\mathrm{N}^{\circ}$ 7-8, pp. 447-454, 2010.

[10] X. Chen and W. Brian,"Analysis and simulation of the grinding process,” Part II: Mechanics of grinding. Int. J. Mach. Tools Manuf, vol. 36, pp. 883-896, 1996.

[11] G. Srihari and G.K. Lal, "Mechanics of vertical surface grinding," J. of Mater. Proces. Tech, vol. 44, pp.14-28, 1994. 